\title{
Growth and Characterization of Piezoelectrically Enhanced Acceptor-Type AlGaN/GaN Heterostructures
}

\author{
A. Michel, D. Hanser*, R.F. Davis* \\ Dept. Chemical Engineering, *Dept. Materials Science and Engineering \\ North Carolina State University, Raleigh, NC 27695 \\ D. Qiao, S.S. Lau, L.S. Yu, W. Sun, P. Asbeck \\ Dept. Electrical and Computer Engineering \\ University of California San Diego, LaJolla, CA 92093-0407
}

\begin{abstract}
Acceptor (Mg)-doped AlGaN/GaN heterostructures were grown via MOVPE and compared to similarly doped $\mathrm{GaN}$ standard films grown in the same reactor. Chemical analysis of the films, via secondary ion mass spectrometry (SIMS), revealed comparable Mg concentrations of $\sim 2 \times 10^{19}$ atoms $/ \mathrm{cm}^{3}$ in all films. The Mg-doped GaN standard sample had a sheet conductance of 7- $\mu \mathrm{S}$ compared to a sheet conductance of 20$\mu \mathrm{S}$ for an $\mathrm{AlGaN} / \mathrm{GaN}$ heterostructure. The sheet conductance of the $\mathrm{AlGaN} / \mathrm{GaN}$ heterostructures was higher due to piezoelectric acceptor doping and modulation doping effects in addition to conventional $\mathrm{Mg}$ acceptor doping.
\end{abstract}

\section{INTRODUCTION}

Heterostructures of $\mathrm{AlGaN}$ and $\mathrm{GaN}$ are being extensively investigated and employed in the fabrication of high electron mobility transistors (HEMT) and heterojunction bipolar transistors (HBT) for high-frequency and high-power applications including microwave amplifiers and compact and efficient power supplies. Prior HEMT research has confirmed the existence of a two-dimensional electron gas (2DEG) at the AlGaN/GaN heterointerface [1]. Strong piezoelectric effects induce a 2D-gas at the $\mathrm{AlGaN} / \mathrm{GaN}$ interface without doping. Electron sheet concentrations as high as $3 \times 10^{13}$ $\mathrm{cm}^{-2}$ have been reported ${ }^{[2]},[3]$.

The development of GaN-based HBTs has received recent attention for high power/switching devices. The intrinsic high breakdown electric field of GaN should permit a GaN collector drift region that can be either much thinner and/or doped much higher relative to other semiconductors with smaller breakdown strengths (about a factor 30 compared to $\mathrm{Si}$ ) ${ }^{[4]}$. Recent reports regarding the electrical properties of GaN/AlGaN HBTs indicate that the resistance in the extrinsic base region is too high to obtain satisfactory common-emitter characteristics [5]. It is desirable to have a p-type base region and the development of nitride-based HBTs centers on developing a more conductive base layer.

Acceptor-type doping of $\mathrm{GaN}$ materials has been problematic due in large part to passivation of $\mathrm{Mg}$ dopants by $\mathrm{H}$. It has been established that $\mathrm{H}$ enhances the incorporation of dopants such as $\mathrm{Mg}$, but the $\mathrm{Mg}-\mathrm{H}$ bonds must be broken by post-growth annealing to achieve activation [6], [7]. However, the large piezoelectric effects from $\mathrm{AlGaN} / \mathrm{GaN}$ heterostructures can potentially contribute significant conductivity in the base material relative to conventional $\mathrm{Mg}$-doping. 
This paper examines the extent of piezoelectric acceptor doping and modulation doping and compares these results with conventional $\mathrm{Mg}$ acceptor doping in $\mathrm{AlGaN} / \mathrm{GaN}$ system. Material characterization including the $\mathrm{Mg}$ concentration profile and $\mathrm{AlGaN} / \mathrm{GaN}$ interface, as determined by secondary electron mass spectrometry (SIMS), are discussed in relation to the sheet conductivity of the films.

\section{EXPERIMENTAL PROCEDURE}

Each heterostructure consisted of a $\mathrm{GaN}(0001)$ film grown at $1000^{\circ} \mathrm{C}$ on an $\mathrm{Al}_{\mathrm{x}} \mathrm{Ga}_{1-\mathrm{x}} \mathrm{N}(0001)$ layer. The latter was deposited at $1020^{\circ} \mathrm{C}$ on an $\mathrm{AlN}(0001)$ buffer layer previously deposited at $1100^{\circ} \mathrm{C}$ on an on-axis $6 \mathrm{H}-\mathrm{SiC}(0001)$ substrate. Figure 1 shows the doping and $\mathrm{Al}$ profiles of the $\mathrm{GaN}$ and $\mathrm{Al}_{\mathrm{x}} \mathrm{Ga}_{1-\mathrm{x}} \mathrm{N}$ layers in selected samples.

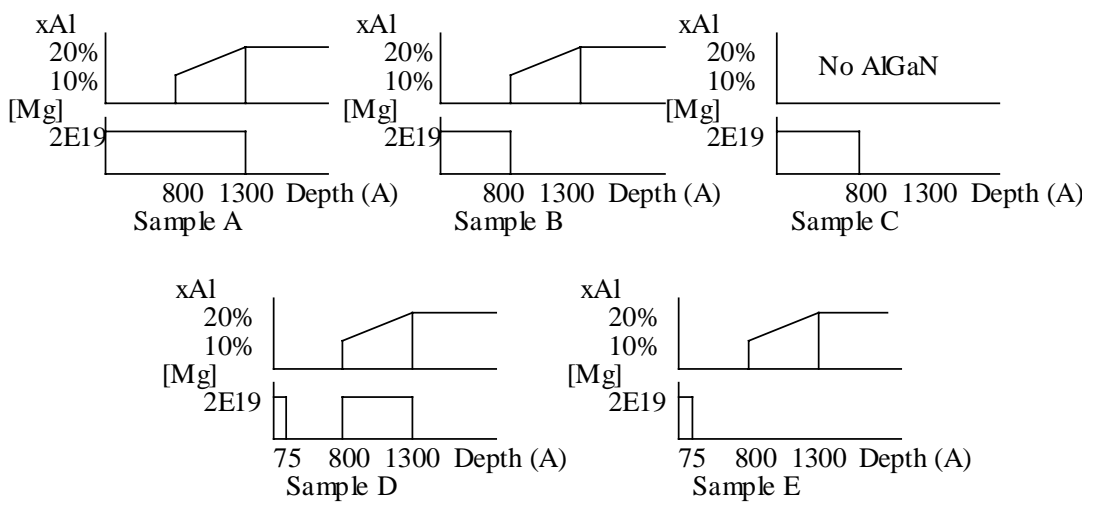

Figure 1. Doping and $\mathrm{Al}$ profiles in selected $\mathrm{GaN} / \mathrm{Al}_{\mathrm{x}} \mathrm{Ga}_{1-\mathrm{x}} \mathrm{N}$ heterostructures. The zero point of the depth scale is the top of the GaN layer.

The AlN buffer layer and all subsequent films were grown in a cold-wall, vertical, pancake-style, RF inductively heated metalorganic vapor phase epitaxy (MOVPE) system. Ammonia $\left(\mathrm{NH}_{3}\right)$, triethylaluminum (TEA) and triethylgallium (TEG) were used as precursors. Bis-cyclopentadienyl-magnesium $\left(\mathrm{Cp}_{2} \mathrm{Mg}\right)$ was employed for the p-type doping. High-purity $\mathrm{H}_{2}$ was used as both the carrier and the diluent gas. After cooling to room temperature the samples were annealed at $800^{\circ} \mathrm{C}$ in $\mathrm{N}_{2}$ to activate the $\mathrm{Mg}$ acceptors. Additional details of the growth experiments in the NCSU reactor have been previously reported [8].

Sample A contains all doping contributions: piezoelectric (PZ), modulation doping (MD) and conventional acceptors (ACC). Sample B lacks the modulation doping component. Sample $\mathrm{C}$ is an $\mathrm{Mg}$-doped $\mathrm{GaN}$ film and is the control sample. It has no PZ charge or modulation doping. Sample D has doping from MD and PZ. Sample E has only PZ doping.

The $\mathrm{Mg}$ concentration profiles and the $\mathrm{Al}$ concentrations were determined using Secondary Ion Mass Spectrometry (Cameca IMS-6f) having a 100nA 10keV O${ }_{2}^{+}$ primary beam. Sputtering rates and $\mathrm{Mg}$ sensitivity factors for varying $\mathrm{Al}$ concentrations have been previously determined ${ }^{[9]}$. Analysis of the AlGaN/GaN interface was conducted by comparing the $\mathrm{Al}$ and Ga signals. Electrical measurements of the films 
were conducted using CV and Hall measurements (van der Pauw configuration). The $\mathrm{Au}(400 \mathrm{~A}) / \mathrm{Ni}(600 \mathrm{~A})$ ohmic contacts were produced by evaporization of the individual metals and subsequently alloying at $650^{\circ} \mathrm{C}$ for 20 minutes. The sheet resistance and the Hall mobility were determined for each layer.

\section{RESULTS AND DISCUSSION}

Magnesium depth profiles determined in Samples A-E are shown in Figure 2.

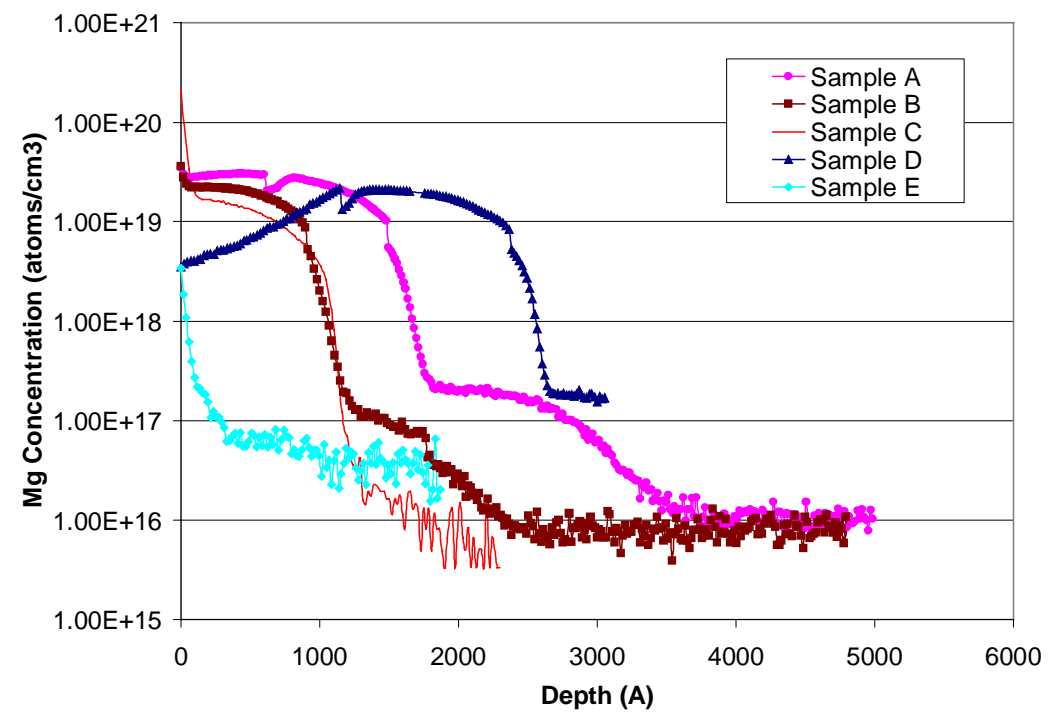

Figure 2. Mg Depth profiles for Samples A-E

The $\mathrm{Mg}$ concentration in the $\mathrm{GaN}$ and the $\mathrm{Al}_{0.1} \mathrm{Ga}_{0.9} \mathrm{~N}$ layers $\sim 2 \times 10^{19}$ atoms $/ \mathrm{cm}^{3}$. A difficulty with $\mathrm{Mg}$ doping is the memory effect in the reactor due to the adsorption of the metal-organic precursor [10]. This leads to slightly higher conductivity from Sample D than expected from a more ideal profile, but does not affect the analysis significantly. The contribution of the polarization to the effective doping contains both a part associated with spontaneous polarization, and a part associated with strain (piezoelectric contribution). The abruptness of the interface affects the distribution of the effective charge (although not its total magnitude, provided there is no lattice relaxation). A total polarization charge as high as $\mathrm{ps} \sim 1 \times 10^{13} \mathrm{~cm}^{-2}$ is expected at an $\mathrm{Al}_{0.25} \mathrm{Ga}_{0.75} \mathrm{~N} / \mathrm{GaN}$ interface [3]. The sharpness of the $\mathrm{AlGaN} / \mathrm{GaN}$ interface in samples investigated in this research is revealed in the SIMS plots of the $\mathrm{Al} / \mathrm{Ga}$ signal ratio as a function of film depth. The $\mathrm{AlGaN} / \mathrm{GaN}$ interface composition varies within a thickness of $300 \AA$. 


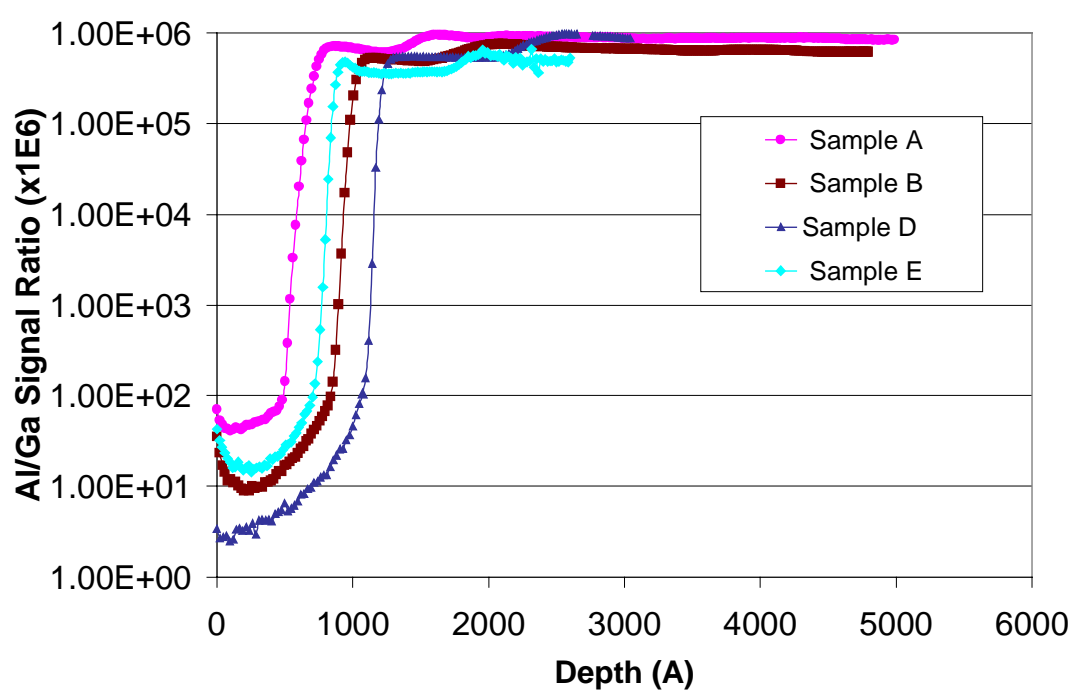

Figure 3. AlGaN/GaN interface

The sheet conductivities of the films with the various doping contributions are presented in Figure 4. The conductivity of Sample E could not be measured.

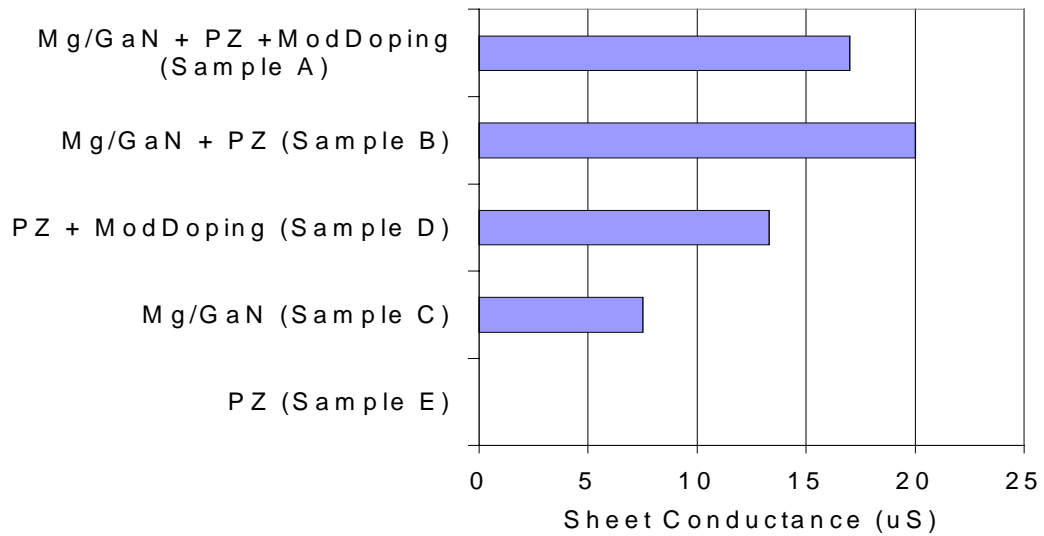

Figure 4. Sheet conductance for Samples A-D.

All samples were more conductive than the Mg-doped GaN standard (Sample C). As all samples contained essentially equal $\mathrm{Mg}$ concentrations, as shown in Figure 3, the electrical data indicate that interfacial strain and modulated doping were effective in increasing the conductivity of the base material. The magnitude of the observed conductivity increase is in good accord with what would be expected on the basis of estimated polarization and modulation doping effects. For example, an added hole 
density of the order of $1 \times 10^{13} \mathrm{~cm}^{-2}$, with a mobility of $10 \mathrm{~cm}^{2} / \mathrm{Vsec}$, would provide an extra component of conductivity of $16 \mathrm{uS}$.

In our experiments, the $\mathrm{GaN}$ layer thicknesses and dopings were chosen to be of the same order as those that could be used in the base layer of an HBT. The AlGaN layers could be used as the emitter layer of the HBT, provided the structure is fabricated with the collector on the wafer surface, and the emitter is grown below the base ("collector-up" device). By contrast, the HBT structures reported to date use an AlGaN emitter on the wafer surface, on top of the GaN base ("emitter-up" device). In these structures (with (0001) films, or Ga-face growth direction), the polarization doping contributions from the emitter-base $\mathrm{AlGaN} / \mathrm{GaN}$ interface provide a donor-like charge, which compensates the Mg-doping contribution, rather than adding to it.

\section{CONCLUSIONS}

Acceptor (Mg)-doped $\mathrm{Al}_{\mathrm{x}} \mathrm{Ga}_{1-\mathrm{x}} \mathrm{N} / \mathrm{GaN}$ heterostructures and a similarly doped GaN standard layer have been grown via MOVPE and the sheet conductance determined from CV measurements. Secondary ion mass spectroscopy shows Mg concentrations in the films of $\sim 2 \times 10^{19} \mathrm{~cm}^{-3}$. The $\mathrm{Mg}$ concentration in all the films was essentially uniform; however, each film possessed a different conductivity depending on the presence and the magnitude of piezoelectric charges and the modulated doping. Additionally SIMS analysis of each film showed a sharp AlGaN/GaN interface $(\sim 300 \AA)$ that enhances both the interfacial strain and the piezoelectric charge. Sheet conductance measurements showed that all $\mathrm{Al}_{\mathrm{x}} \mathrm{Ga}_{1-\mathrm{x}} \mathrm{N} / \mathrm{GaN}$ heterostructures exhibited greater conductivity than the pure GaN sample. This strongly indicates that piezoelectric doping and modulated doping increase the base material conductivity over that achieved by conventional acceptor doping.

\section{Acknowledgement:}

The authors acknowledge Cree Research, Inc. for the SiC wafers. This work is supported by the Office of Naval Research under contracts N0W14-98-1-0654 (John Zolper, monitor).

\section{REFERENCES}

1 A. Bykhovski, B. Gelmont, M. Shur, J. Appl. Phys. 74, 6734 (1993).

2 P. M. Asbeck, E.T. Yu, S.S. Lau, G.J. Sullivan, J. VanHove, J.M. Redwing, Electron. Lett. 33, 1230 (1997).

3 E. T. Yu, G.J. Sullivan, P.M. Asbeck, C.D. Wang, D. Qiao, S. Lau, Appl. Phys. Lett. 71, 2794 (1997).

4 H. Morkoc, R. Cingolani, W. Lambrecht, B. Gil, H.-X. Jiang, J. Lin, D. Pavlidis, K. Shenai, MRS Internet J. Nitride Semicond. Res. 4S1, G1.2 (1999).

5 J. Han, A.G. Baca, R.J. Shul, C.G. Willison, L. Zhang, F. Ren, A.P. Zhang, G.T. Dang, S.M. Donovan, X.A. Cao, H. Cho, K.B. Jung, C.R. Abernathy, S.J. Pearton, R.G. Wilson, Appl. Phys. Lett. 74, 2702 (1999).

6 S. Nakamura, T. Mukai, M. Senoh, Appl. Phys. Lett. 64, 1687 (1994).

7 F. A. Reboredo, S.T. Pantelides, MRS Internet J. Nitride Semicond. Res. 4S1, G5.3 (1999).

8 W. Weeks, M. Bremser, K. Alley, E. Carlson, Appl. Phys. Lett. 67, 401 (1995). 
D. P. Griffis, R. Loesing, D.A. Ricks, M.D. Bremser, R.F. Davis, in Quantitative Analysis of $\mathrm{C}, \mathrm{O}, \mathrm{Si}$ and $\mathrm{Mg}$ Impurities in AlGaN, Orlando, FL, 1997 (John Wiley and Sons), p. 201-204.

10

Y. Ohba, A. Hatano, J. Cryst. Growth 145, 214 (1994).

F99W11.8

https://doi.org/10.1557/S1092578300004828 Published online by Cambridge University Press 